Article publié par le Laboratoire de Construction en Béton de l'EPFL

\begin{tabular}{|l|l|}
\hline Title: & Test and lower bound modeling of keyed shear connections in RC shear walls \\
\hline Authors: & Sorensen J. H., Herfelt M. A., Hoang L. C., Muttoni A. \\
\hline Published in: & Engineering Structures \\
\hline DOI & $10.1016 /$ j.engstruct.2017.11.004 \\
\hline $\begin{array}{l}\text { Volume: } \\
\text { Pages: }\end{array}$ & $\begin{array}{l}155(2018) \\
\text { pp. 115-126 }\end{array}$ \\
\hline Year of publication: & 2017 \\
\hline Type of publication: & Peer reviewed journal article \\
\hline
\end{tabular}

Please quote as: modeling of keyed shear connections in RC shear walls, Engineering Structures, 155 (2018), 2017, pp. 115-126. 


\title{
Test and lower bound modeling of keyed shear connections in RC shear walls
}

\author{
Jesper Harrild Sørensen ${ }^{\mathrm{a}, *}$, Morten Andersen Herfelt ${ }^{\mathrm{a}, \mathrm{b}}$, Linh Cao Hoang ${ }^{\mathrm{a}}$, Aurelio Muttoni ${ }^{\mathrm{c}}$ \\ a Technical University of Denmark, Department of Civil Engineering, Brovej, Bygning 118, 2800 Kgs. Lyngby, Denmark \\ b Niras A/S, Sortemosevej 19, 3450 Allerød, Denmark \\ ${ }^{\mathrm{c}}$ Ècole Polytechnique Fédérale de Lausanne, ENAC, Station 18, CH-1015 Lausanne, Switzerland
}

\section{A R T I C L E I N F O}

\section{Keywords:}

Keyed shear connections

Precast concrete

Push-off tests

Rigid-plasticity

Lower bound solutions

\begin{abstract}
A B S T R A C T
This paper presents an investigation into the ultimate behavior of a recently developed design for keyed shear connections. The influence of the key depth on the failure mode and ductility of the connection has been studied by push-off tests. The tests showed that connections with larger key indentations failed by complete key cut-off. In contrast, connections with smaller key indentations were more prone to suffer local crushing failure at the key corners. The local key corner crushing has an effect on the load-displacement response, which is relatively more ductile. In addition to the tests, the paper also presents lower bound modeling of the load carrying capacity of the connections. The main purpose of the lower bound model is to supplement an already published upper bound model of the same problem and thereby provide a more complete theoretical basis for practical design. The two models display the same overall tendencies although identical results are not possible to obtain, due to differences in the basic assumptions usually made for upper and lower bound analysis of connections. It is found that the test results, consistent with the extremum theorems of plasticity, are all lying within the gap between the upper and the lower bound solution. The obtained results finally lead to a discussion of how the two models can be used in practice. The primary merit of the upper bound model lies in its simplicity (a closed-form equation). On the other hand, the lower bound model provides safe results, but is more complicated to apply. It is therefore argued that the upper bound model may be used in cases, where calibration with tests has been carried out. The lower bound model should be applied in situations, where the design deviates significantly from the configurations of the available tests.
\end{abstract}

\section{Introduction}

A new design for keyed shear connections between precast wall elements has recently been proposed and the structural performance has been experimentally investigated [1]. The conceptual layout of the design can be seen in Fig. 1. Unlike the conventional solution, where the overlapping U-bars are looped in the horizontal plane [2,3], this new layout consists of U-bars looped in vertical planes. The solution contains double T-headed bars (lacer bars) placed perpendicular to the plane of the wall elements to ensure efficient transfer of tension between the U-bars [4]. It is also possible to add a vertical locking bar similar to the conventional design of keyed shear connections. As shown in [1], the new design has a much more ductile shear behavior than the conventional solution and can in addition be more construction-friendly in case of vertically lowered panels. Thus, the new design has the potential to be used in e.g. high-rise buildings in cases where in situ walls are replaced by precast concrete elements.
The experimental results reported in [1] showed that the geometry of the shear keys, and in particular the depth of the keys, plays an important role for the ductility of the connection. In addition, the ability of the U-bars to develop yielding is decisive for a desirable behavior of the connection in the ultimate limit state. Inspired by experimental observations, rigid-plastic upper bound solutions have been developed for prediction of the capacity of the connection [1].

The aim of this paper is twofold. First and foremost, there is a need for additional tests to explore the behavior of the new design and in details study the influence of the key depth. Therefore, an in-depth experimental investigation of the failure of the shear keys has been carried out. To widen the experimental database (not only with respect to the number of tests but also with respect to parameter variations) Ubar diameters smaller than those used in the first test campaign have been investigated. Secondly, from an analytical point of view, there is a need to establish lower bound solutions for the shear capacity of the connections in order to evaluate the already developed upper bound

\footnotetext{
* Corresponding author.

E-mail address: jhaso@byg.dtu.dk (J.H. Sørensen).
} 


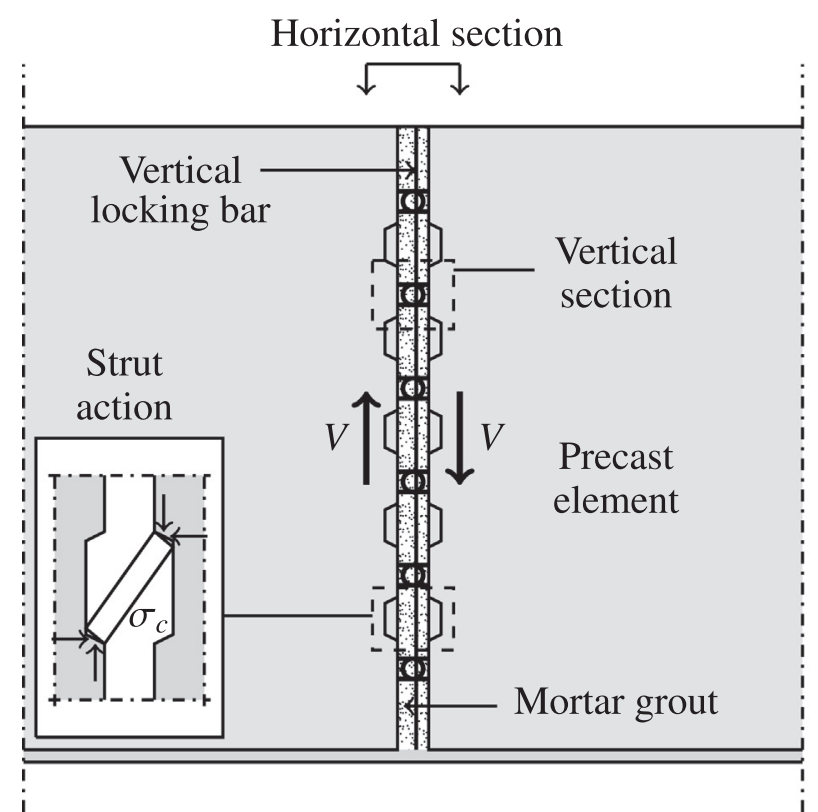

(a)

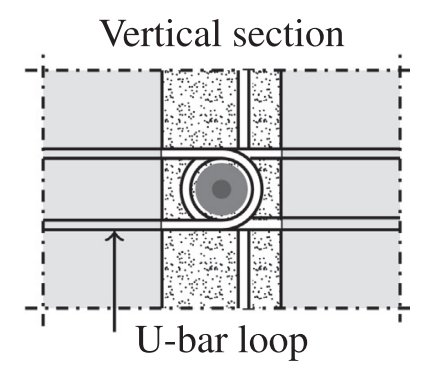

Fig. 1. (a) Shear connection between RC precast wall elements and (b) conceptual design of new connection solution (illustrations from [4]). solutions [1]. The set of solutions can be used to bracket the theoretically exact solution from below and above, which is extremely useful for practice.

For looped connections, upper bound solutions are relatively straight forward to establish when based on observed failure modes $[1,5,6]$, while optimal lower bound solutions are more difficult to develop. Simple lower bound solutions for keyed shear connections have e.g. been proposed by Christoffersen [7] and further developed in Nielsen and Hoang [8]. However, the models contain only single uniaxial strut action and are in many cases too conservative. Recently, Herfelt et al. [9] presented a numerical framework for obtaining optimal lower bound solutions based on finite element limit analysis (FELA). The numerical tool calculates the optimal stress distribution and the corresponding failure mechanism in the joint mortar. In this paper the results obtained by FELA will be used as inspiration to establish analytical lower bound solutions.

Compared to the single strut solution [7], the following numerical and analytical models utilize combinations of struts with different inclinations to optimize the theoretical load carrying capacity. In addition, the ability of the grout-to-panel interface to transfer shear stresses is utilized which eventually leads to non-hydrostatic biaxial stress conditions in the nodal zones. The stresses in the nodal zones at the key corners are modeled by use of the concept of homogeneous stress fields. The concept was treated e.g. in Refs. [10-12].

\section{Experimental program}

The experimental program comprised 12 push-off specimens with identical loop configuration and with a variation of the key depth, $d_{k}$, from $10 \mathrm{~mm}$ to $20 \mathrm{~mm}$. Compared to the first test campaign [1], this program used U-bars with a diameter of $6 \mathrm{~mm}$ instead of $8 \mathrm{~mm}$ and the shear keys in all specimens had a height equal to the thickness of the precast element, i.e. $h_{k}=t$, which enabled identification of the local failure of the individual shear keys by use of digital image correlation (DIC). The general geometry of the test specimens can be seen in Fig. 2 and the material properties are given in Tables 1 and 2 . The specimen identification refers to the depth of the shear keys (e.g. D10 designates a key depth of $d_{k}=10 \mathrm{~mm}$ ). Each design was replicated twice, denoted A and $\mathrm{B}$. The connections were grouted with a mortar with a maximum aggregate size of $4 \mathrm{~mm}$ and a vertical locking bar was included to minimize the extent of diagonal cracking between the shear keys. The

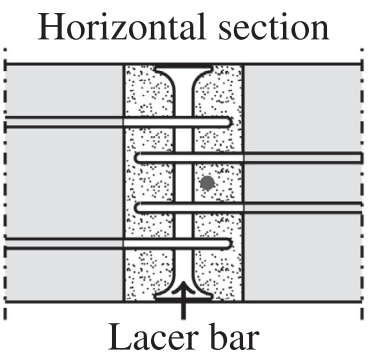

(b)

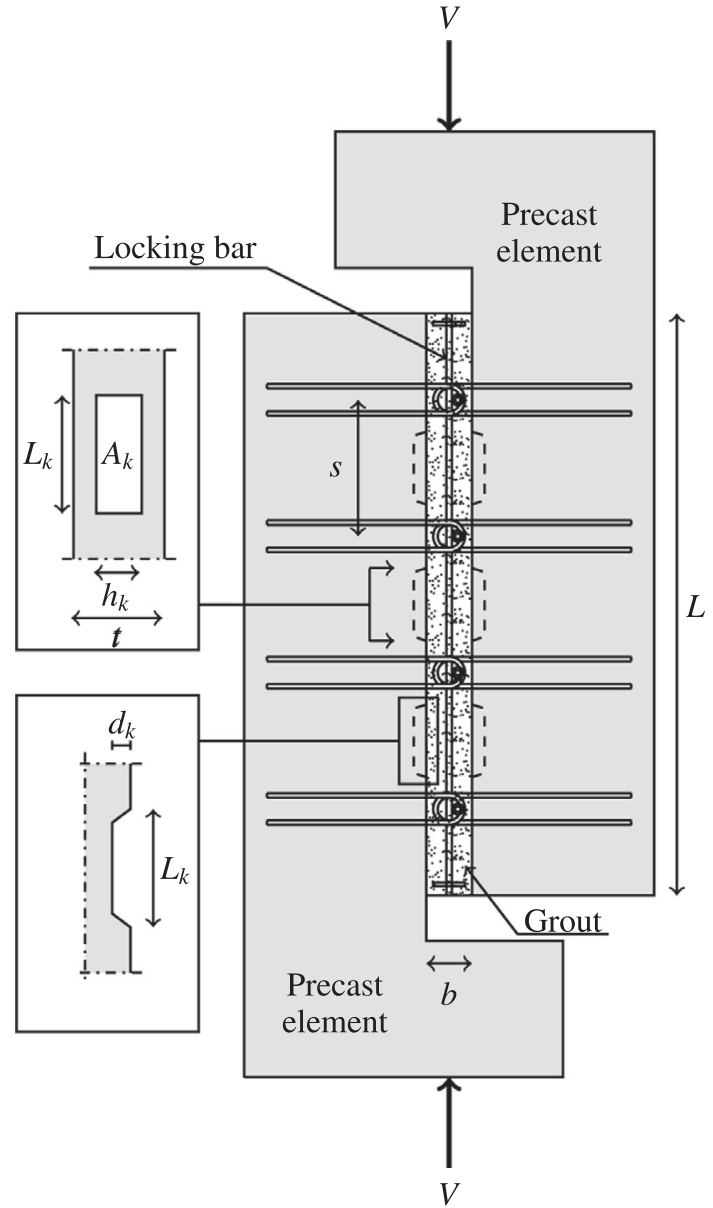

Fig. 2. General layout of push-off test specimens (illustration from [1]). 
Table 1

Specifications of the test specimens, including material properties.

\begin{tabular}{cccccccc}
\hline & No. & $f_{c}[\mathrm{MPa}]$ & $L_{k}[\mathrm{~mm}]$ & $A_{k}\left[\mathrm{~mm}^{2}\right]$ & $d_{k}[\mathrm{~mm}]$ & $A_{s}\left[\mathrm{~mm}^{2}\right]$ & $V_{\mathrm{FP}}[\mathrm{kN}]$ \\
\hline \multirow{2}{*}{ 10 } & A & 44.6 & 120 & 24000 & $\mathbf{1 0}$ & 113 & 448.56 \\
& B & 44.6 & 120 & 24000 & $\mathbf{1 0}$ & 113 & 448.62 \\
$\mathrm{D} 12$ & A & 44.6 & 120 & 24000 & $\mathbf{1 2}$ & 113 & 471.74 \\
& B & 44.6 & 120 & 24000 & $\mathbf{1 2}$ & 113 & 496.36 \\
D14 & A & 44.6 & 120 & 24000 & $\mathbf{1 4}$ & 113 & 510.91 \\
& B & 44.6 & 120 & 24000 & $\mathbf{1 4}$ & 113 & 519.16 \\
D16 & A & 44.6 & 120 & 24000 & $\mathbf{1 6}$ & 113 & 543.30 \\
& B & 44.6 & 120 & 24000 & $\mathbf{1 6}$ & 113 & 541.57 \\
D18 & A & 42.0 & 120 & 24000 & $\mathbf{1 8}$ & 113 & 540.73 \\
& B & 42.0 & 120 & 24000 & $\mathbf{1 8}$ & 113 & 537.50 \\
D20 & A & 42.0 & 120 & 24000 & $\mathbf{2 0}$ & 113 & 526.62 \\
& B & 42.0 & 120 & 24000 & $\mathbf{2 0}$ & 113 & 517.03 \\
\hline
\end{tabular}

$f_{c}$ refers to the compressive strength of the grout measured on $\phi 100 \times 200 \mathrm{~mm}$ cylinders.

$A_{S}$ describes the reinforcement area per loop connection, i.e. $4 \frac{\pi}{4} \phi^{2}$.

Table 2

Material properties and geometric values.

\begin{tabular}{lcc}
\hline Description & Symbol & \\
\hline U-bar diameter & $\phi$ & $6 \mathrm{~mm}$ \\
Yield strength of U-bar & $f_{y}$ & $517 \mathrm{MPa}$ \\
Lacer bar diameter & $\phi_{\text {Lacer }}$ & $12 \mathrm{~mm}$ \\
Yield strength of lacer bar & $f_{y, \text { Lacer }}$ & $552 \mathrm{MPa}$ \\
Internal bend diameter of loops & $D$ & $45 \mathrm{~mm}$ \\
Width of Joint & $b$ & $80 \mathrm{~mm}$ \\
Distance between loops & $s$ & $300 \mathrm{~mm}$ \\
Inclination of key corner & $\theta_{k}$ & $\arctan \frac{1}{2}$ \\
Total length of joint & $L$ & $1280 \mathrm{~mm}$ \\
Max aggregate size in mortar & $d_{\text {max }}$ & $4 \mathrm{~mm}$ \\
Diameter of locking bar & $\phi_{L}$ & $12 \mathrm{~mm}$ \\
Yield strength of locking bar & $f_{y L}$ & $599 \mathrm{MPa}$ \\
Panel thickness & $t$ & $200 \mathrm{~mm}$ \\
Strength of precast panels & $f_{c, \text { element }}$ & $58.2 \mathrm{MPa}$ \\
\hline
\end{tabular}

U-bar loops were designed according to Refs. [4,6] to transfer the full yield force of the U-bars.

\subsection{Test results}

Fig. 3 shows examples of typical tested load-displacement relationships. The depicted displacements correspond to relative longitudinal displacements between the two precast elements, measured at both ends of the connection and averaged. The figure shows two

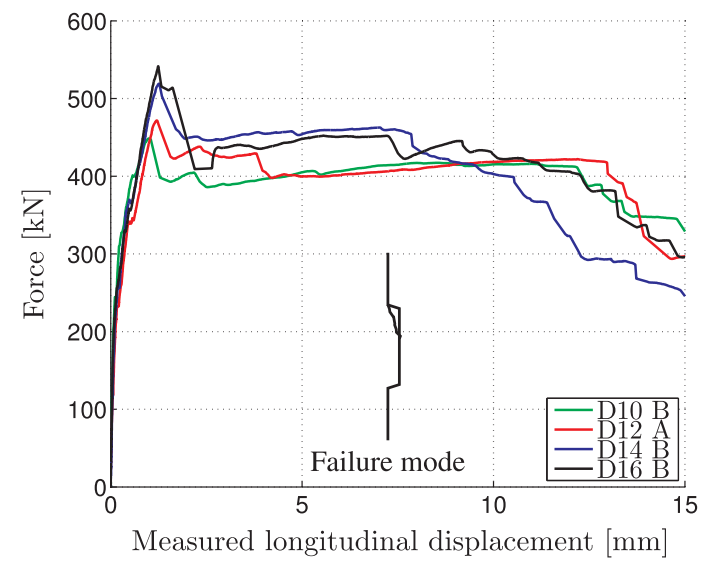

(a) Smaller key depths, failure by key corner shearing different behaviors depending on the failure mode of the shear keys. The plots in Fig. 3(a) are the results of specimens with smaller key depths $\left(d_{k}=10-16 \mathrm{~mm}\right)$ where failure took place as a local shearing of the key corners (as illustrated in the graph). For larger key depths $\left(d_{k}=16-20 \mathrm{~mm}\right)$, complete shearing of the shear keys governed the first peak load, which leads to the load-displacement characteristics shown in Fig. 3(b).

The transition from key corner shearing to complete key shearing was dependent on a number of factors, including the geometry of the shear keys, the material properties of the mortar, and the strength of the reinforcement. From post-test examinations it was found that specimens with $d_{k}=16 \mathrm{~mm}$ could fail both by local key corner shearing (D16B) and by complete failure of the shear key (D16A). This indicates that the theoretical transition between the two failure modes for this particular test series takes place at approximately this key depth. The load-displacement relationships of D16A and D16B are both shown in Fig. 3. It was found that both had comparable first peak loads, $V_{\mathrm{FP}}$ (see Table 1). However, the residual load level after first peak was higher for specimen D16B which experienced key corner shearing. This was a general observation that specimens suffering local key corner shearing had a more ductile load-displacement relationship (i.e. residual load level closer to first peak load). In contrast to this, a relatively larger drop of the load immediately after first peak was observed for all the specimens, which failed by complete key shearing. Both types of failure were accompanied by development of diagonal cracks in the grout. Fig. 4 shows examples of local failure of the keys in combination with diagonal cracks which formed the global failure mechanism. Post-test examinations also showed large plastic deformations in the U-bars. This observation confirms that the design of the loop connection (i.e. the overlapping length, the diameter of lacer bar and the internal bend diameter of the U-bars) did enable transfer of the yield capacity of the U-bars through the overlap.

It was generally observed that the first peak load, $V_{\mathrm{FP}}$, increased with increasing key depth until complete shearing of the keys becomes the critical failure mode. Then $V_{\mathrm{FP}}$ remained practically constant and independent of a further increase of the key depth, cf. Table 1 . The residual load level after first peak appeared somewhat constant within the two types of failure and must thereby be related to the layout and the properties of the loop reinforcement, which were kept constant in this study.

Based on the experimental results, it seems that connections in practice should be designed to be governed by local shearing of the key corners, as this minimizes the difference between first peak load and the residual load level.

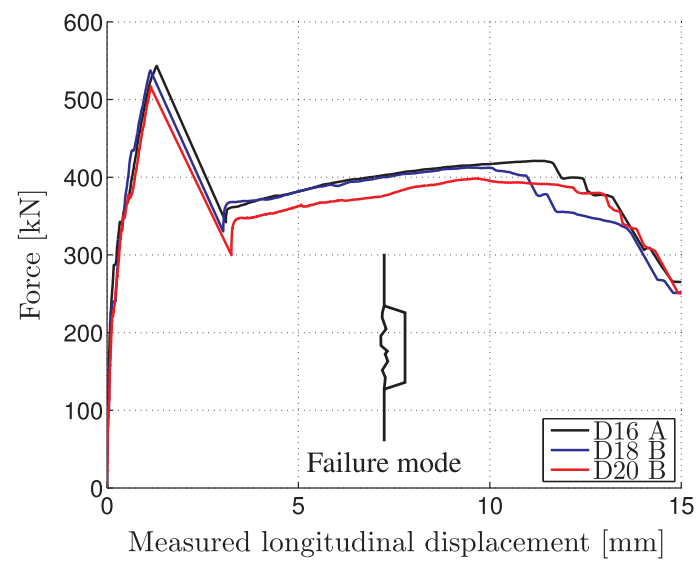

(b) Larger key depths, failure by complete key shearing

Fig. 3. Experimentally recorded load-displacement curves. 


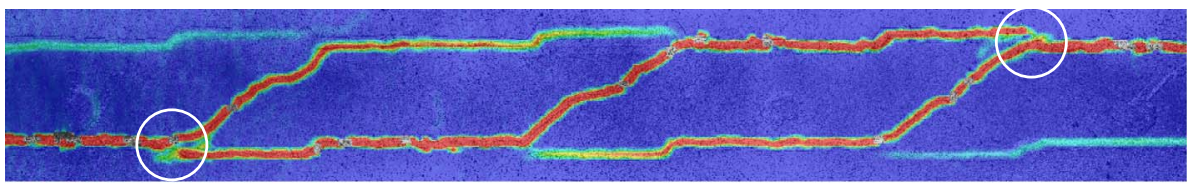

(a) Specimen D10 A - key corner shearing

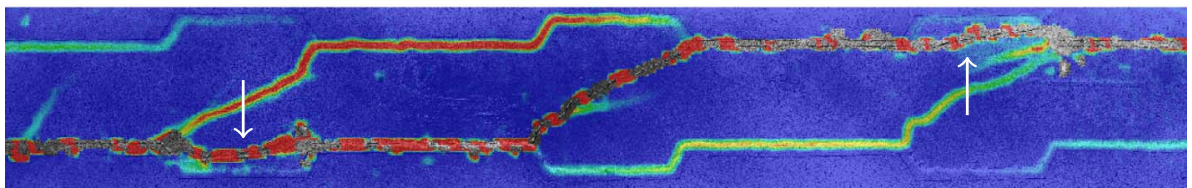

(b) Specimen D20 A - complete key shearing

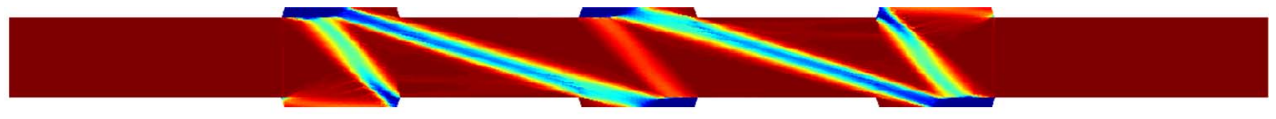

Fig. 5. Distribution of the smallest principal stress (MPa, tension positive) in connections with $d_{k}=10,14$ and $20 \mathrm{~mm}$, obtained by FELA, $f_{c}=42 \mathrm{MPa}$.

(a) $d_{k}=10 \mathrm{~mm}, V_{F P}=340.5 \mathrm{kN}$

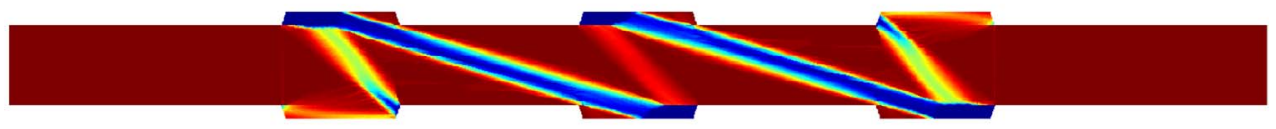

(b) $d_{k}=14 \mathrm{~mm}, V_{F P}=404.1 \mathrm{kN}$

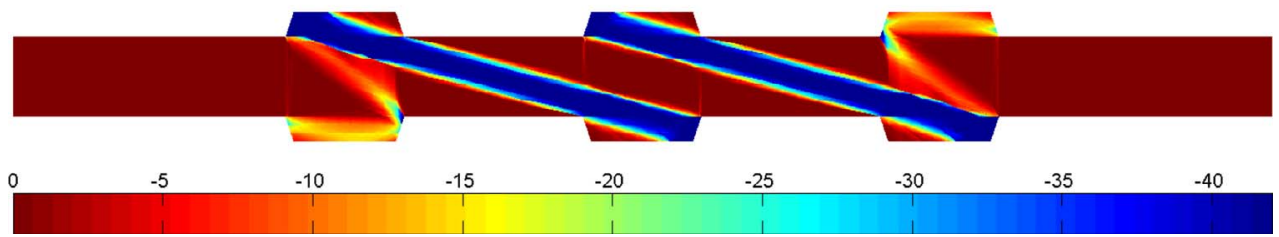

(c) $d_{k}=20 \mathrm{~mm}, V_{F P}=486.1 \mathrm{kN}$

\section{Rigid-plastic analysis}

The first peak load, $V_{\mathrm{FP}}$, can be estimated by use of upper or lower bound models assuming rigid-plastic material behavior. Rigid-plastic modeling can also be used to obtain an estimate of the inelastic load-displacement curve. This, however, requires a second order plastic analysis where change of geometry and large displacements are taken into account [13-16].

The objective of this paper is limited to the calculation of $V_{\mathrm{FP}}$. As mentioned, an upper bound model has already been established [1]. The model predicts the shear capacity of keyed connections in a satisfactory manner provided that an effectiveness factor, $v$, is introduced. The problem, however, with a pure upper bound approach is that it remains an open question whether the adopted effectiveness factor, obtained by calibration with tests, to a significant extent also accounts for the fact, that the developed upper bound model is not necessarily the exact/correct one. To answer the question and eventually to evaluate the developed upper bound model, lower bound solutions will be established in the following. This includes both numerical solutions as well as analytical ones.

\section{Numerical lower bound solutions based on finite element limit analysis (FELA)}

The main purpose of the performed numerical lower bound calculations is to provide inspiration for the type of stress field to be adopted in an analytical lower bound model. FELA can be considered as a special case of the finite element method, where a rigid-plastic material model is assumed. For lower bound solutions, a set of constraints ensure that the equilibrium conditions and the yield criteria are satisfied, i.e. a statically admissible and safe stress field, while the load is sought to be maximized. A detailed description of the numerical framework for modeling of keyed connections can be found in Herfelt et al. [9] and a summary of the concept is given in Appendix A. Here only the main assumptions are needed for comparison with the analytical model.

The relevant parameters for the numerical analysis are the geometry of the shear keys, the mechanical degree of transverse reinforcement, interface properties, and the grout properties. Based on the experimental results the transverse reinforcement degree is determined by the yield force of the U-bars. In the model, the overlapping loops are simplified as continuous reinforcement crossing the connection. Moreover, plane stress condition is assumed and the mortar is modeled as a modified Coulomb material without tensile strength. For the interface between the grout and the precast concrete, a Coulomb friction criterion is assumed with a friction coefficient, $\mu=0.75$ (corresponding to smooth casting joints $[8,17]$ ) and a neglectable cohesion. However, friction is only considered active in the indented areas. The main argument for this is that the normal stress required to activate friction stems from tension in the transverse reinforcement, which represents a form of passive confinement in contrast to active confinement from an external normal force. Hence, since the load is anticipated to be carried mainly by strut action between the shear keys (when no active normal force is applied), then only the indented areas (which experiences compression from the strut action) can transfer friction. The 
longitudinal locking bar has not been included in the numerical model, as it is judged to entail stress fields that, at the current stage, are too complicated for the initial establishment of analytical lower bound models.

Fig. 5 shows the calculated distribution of the smallest principal stress (maximum compressive stress) in the joint mortar for some specimens from the experimental program. The stress field is only visualized for the joint mortar, since the precast elements in the experimental program as well as in the numerical model had over-strength. In the calculations, the strength of the mortar was taken as $f_{c}$, according to Table 1 . This entails that the effectiveness factor, $\nu$, was chosen as unity (note that the absolute value of $\nu$ is not important when the results are used only to compare with the analytical solutions).

From the optimized stress distributions, it can be seen that the load transfer mechanism consists of a combination of compression struts spanning over one or two shear keys, i.e. struts with different inclinations. This type of stress field is obviously more complicated than the single strut solutions [7]. The numerical results will in the following form the basis for how to choose the stress field in an analytical lower bound solution and finally the results of the two methods will be compared.

\section{Analytical lower bound solutions}

Inspired by the results of FELA, an analytical model for the load carrying capacity of keyed shear connections will be established. Some simplifications have to be introduced in order to carry out the analytical calculations. Two basic stress fields are considered, in the following denoted as Solution 1 and Solution 2, and the contribution from the locking bar is disregarded. Solution 1 consists of parallel struts spanning over a single shear key (Fig. 6). Solution 2 combines struts spanning over one shear key and two shear keys, respectively (Fig. 8). The struts carry uniaxial compression, while the nodal zones are stressed in biaxial compression. A lower bound for the load carrying capacity will in this context be taken as the larger of the two solutions. It turns out that Solution 1 is optimal for smaller key depths, whereas Solution 2 is optimal for larger key depths. For a further increase of the key depth, the load may be carried almost completely by struts spanning over two shear keys without combination with struts over a single key, see e.g. Fig. 5(c). This is in accordance with the model of Christoffersen [7] (see also Nielsen and Hoang [8]).

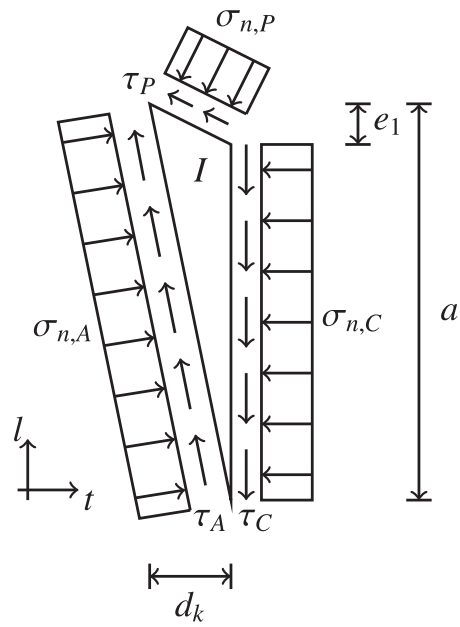

(a)

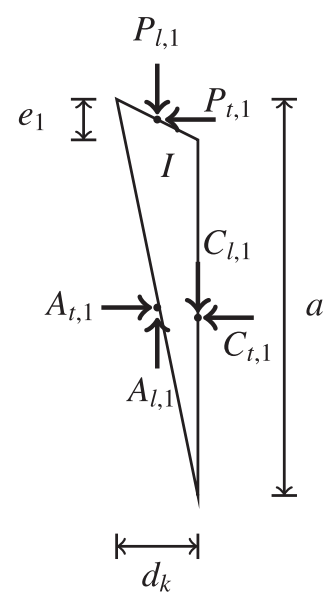

(b)
Fig. 7. (a) Stresses along boundaries of Triangle $I$ (Solution 1) and (b) resultants of stresses on boundaries.

\subsection{Solution 1: Single struts spanning over one shear key}

For the purpose of analysis, a $l-t$ coordinate system, referring to the longitudinal and transverse directions of the connection, is defined, see Fig. 6 . The following relations for the geometrical parameters shown in Fig. 6 are introduced:

$\tan \theta_{k}=\frac{e_{1}}{d_{k}}$

$\tan \theta_{A, 1}=\frac{L_{k}-e}{b}$

$a=e-d_{k} \tan \theta_{A, 1}$

In Fig. 6(b) the parameter $e$ is an optimization parameter related to the strut width. The capacity obtained by this solution is governed by either the compressive strength of the strut or the stress state in the key corner (in the following denoted Triangle $I$ ), which can be assessed as a homogeneous stress field. The stress components for this solution will be calculated in the following.

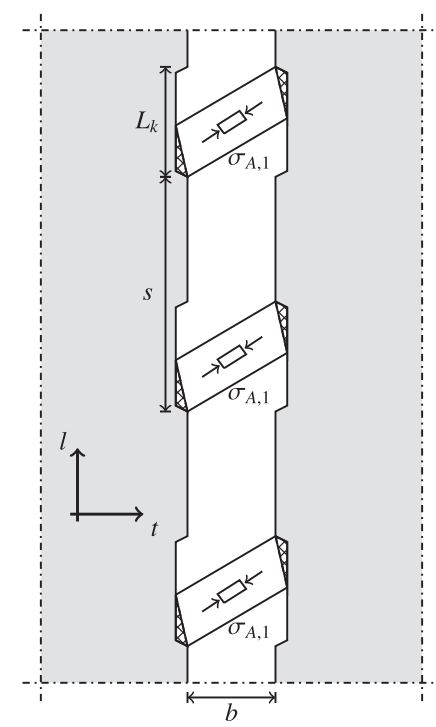

(a)

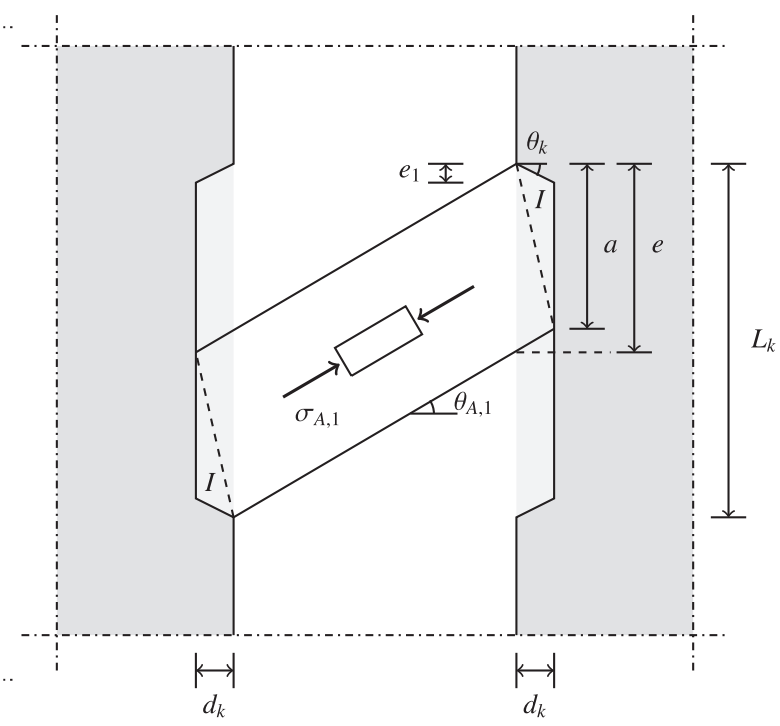

(b)
Fig. 6. (a) Distribution of struts spanning over a single key (Solution 1) and (b) definition of geometrical parameters at a key including the nodal zone, Triangle $I$. 


\subsubsection{Local equilibrium conditions for Solution 1}

Fig. 7(a) depicts the nodal zone (Triangle $I$ ) of Solution 1 where each of the three boundaries is assumed to be uniformly stressed by normal and shear stresses. The stress field within the triangle is thus homogeneous. Compressive normal stresses are taken as positive. The stress resultants on the boundaries act at the centroid of each boundary and are illustrated in Fig. $7(\mathrm{~b})$ as forces related to the $l-t$ coordinate system.

The homogeneous stress field $\left(\sigma_{t}, \sigma_{l}, \tau_{l t}\right)$ within Triangle $I$ may be expressed in terms of the stress resultants shown in Fig. 7(b):

$\sigma_{t, I}=\frac{C_{t, 1}}{\left(a-e_{1}\right) h_{k}}$

$\sigma_{l, I}=\frac{A_{l, 1} \frac{a-e_{1}}{a}-C_{l, 1}}{d_{k} \frac{a-e_{1}}{a} h_{k}}$

$\tau_{t l, I}=\frac{C_{l, 1}}{\left(a-e_{1}\right) h_{k}}$

The relations between $\sigma_{A, 1}$ and the stress resultants, $A_{l, 1}$ and $A_{t, 1}$, are:

$A_{l, 1}=\sigma_{A, 1} \cos \theta_{A, 1} \sin \theta_{A, 1} h_{k} e$

$A_{t, 1}=\sigma_{A, 1} \cos ^{2} \theta_{A, 1} h_{k} e$

From the three equilibrium conditions for the triangular area, the following relations between the stress resultants can be established:

$A_{l, 1}-C_{l, 1}-P_{l, 1}=0$

$A_{t, 1}-C_{t, 1}-P_{t, 1}=0$

$A_{t, 1} \frac{a-e_{1}}{2}-C_{l, 1} \frac{d_{k}}{2}-C_{t, 1} \frac{a}{2}=0$

\subsection{Solution 2: Combination of struts spanning over one and two shear keys}

In this solution, the struts are assumed to span in such a way so that the entire key length, $L_{k}$, is utilized to transfer stresses (compare Fig. 8(b) to Fig. 6(b)). Similar distributions can be seen in Fig. 5. The inclination of Strut $A$ may also in this case be described by Eq. (2). The inclination of Strut $B$ spanning over two keys is: $\tan \theta_{B}=\frac{s-e}{b}$

where $s$ is the distance between the shear keys and $e$ describes the same geometrical parameter as in Solution 1, see Fig. 8(b). As indicated in Fig. 8(b) the nodal zone in the indented area has been subdivided into two triangular areas (II and III), which as shown later are stressed in biaxial compression. To describe the geometry of this zone, the distance $e_{2}$ is introduced as follows:

$e_{2}=L_{k}-\left(e+d_{k} \tan \theta_{B}\right)$

This relation ensures that the above mentioned assumption of stress transfer over the entire indented length, $L_{k}$, is fulfilled. In this context, it is assumed that $e_{2}$ cannot attain negative values, and to fulfill this, a maximum effective key depth that can be utilized in the model is introduced:

$d_{k, \mathrm{ef}}=\left(L_{k}-e\right) \cot \theta_{B}$

Hence, for larger key depths, the maximum effective key depth, $d_{k, \text { ef }}$, is adopted in the calculations. This eventually means that by using Solution 2, a capacity higher than that corresponding to a key depth of $d_{k, \mathrm{ef}}$ cannot be obtained. As for Solution 1, the capacity here will also be governed by either the stress state in the struts or in the triangles.

\subsubsection{Local equilibrium conditions for Solution 2}

The equilibrium equations for Triangle $I$ in Solution 1 also apply for Solution 2 in which the outermost shear keys also contain a nodal zone of the same type, see Fig. 8(b). In addition, equilibrium equations for the nodal zone bounding Strut $A$ as well as Strut $B$, i.e. Triangles $I I$ and III, need to be developed. The stresses and stress resultants acting on the boundaries of Triangle $I I$ and III are illustrated in Fig. 9. Triangle III borders on Struts $A$ and $B$ as well as Triangle II.

The homogeneous stress fields within Triangle II and Triangle III can be expressed in terms of the stress resultants (by use of equilibrium considerations). These stresses are:

$\sigma_{t, I I}=\frac{C_{t, 2}}{\left(e+e_{2}-e_{1}\right) h_{k}}$

$\sigma_{l, I I}=\frac{F_{l} \frac{e+e_{2}-e_{1}}{e+e_{2}}-C_{l, 2}}{d_{k} \frac{e+e_{2}-e_{1}}{e+e_{2}} h_{k}}$

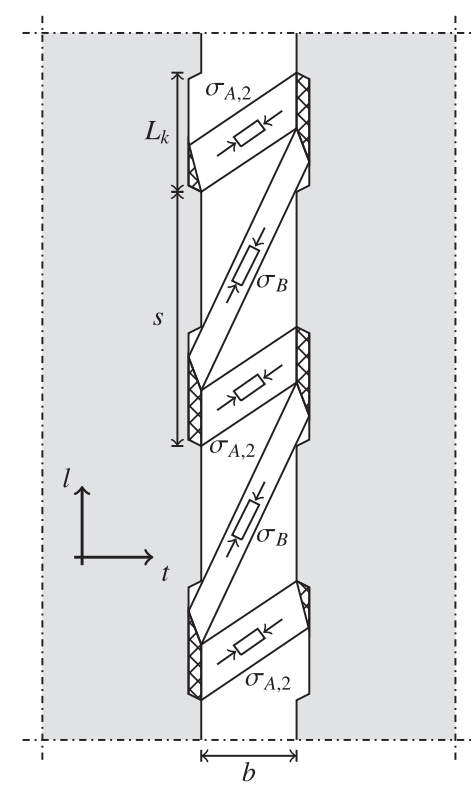

(a)

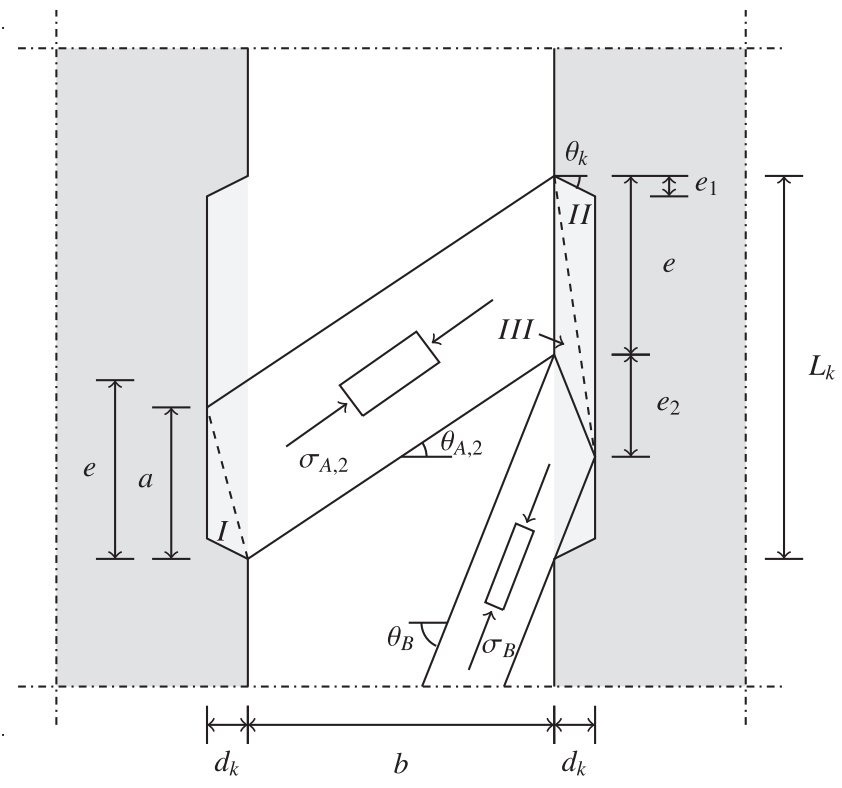

(b)
Fig. 8. (a) Distribution of struts in joint mortar (Solution 2) and (b) geometry at a key for verification of stress transfer. 


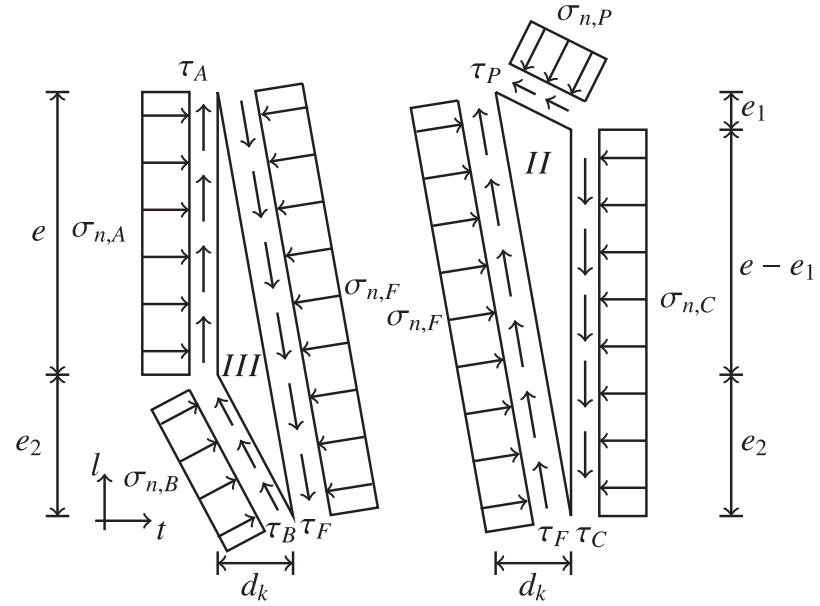

(a)
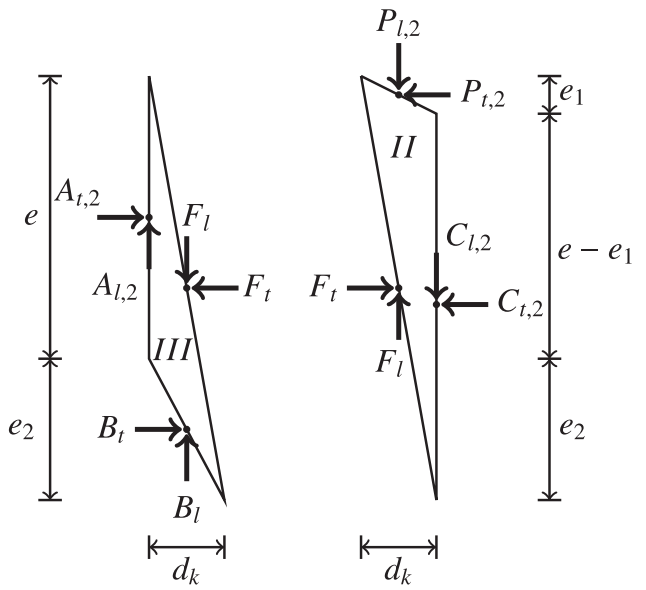

(b)

Fig. 9. (a) Stresses along boundaries of Triangles II and III (Solution 2) and (b) resultants of stresses on boundaries.

$\tau_{t l, I I}=\frac{C_{l, 2}}{\left(e+e_{2}-e_{1}\right) h_{k}}$

$\sigma_{t, I I I}=\frac{A_{t, 2}}{e h_{k}}$

$\sigma_{l, I I I}=\frac{B_{l}-F_{l} \frac{e_{2}}{e+e_{2}}}{d_{k} \frac{e}{e+e_{2}} h_{k}}$

$\tau_{t l, I I I}=\frac{A_{l, 2}}{e h_{k}}$

The relations between $\sigma_{A, 2}, \sigma_{B}$, and their stress resultants are given by:

$A_{l, 2}=\sigma_{A, 2} \cos \theta_{A, 2} \sin \theta_{A, 2} h_{k} e$

$A_{t, 2}=\sigma_{A, 2} \cos ^{2} \theta_{A, 2} h_{k} e$

$B_{l}=\sigma_{B} \cos \theta_{B} \sin \theta_{B} h_{k}\left(L_{k}-e\right)$

$B_{t}=\sigma_{B} \cos ^{2} \theta_{B} h_{k}\left(L_{k}-e\right)$

From the three equilibrium conditions for Triangle III, the following relations are established:

$A_{l, 2}+B_{l}-F_{l}=0$

$A_{t, 2}+B_{t}-F_{t}=0$

$\sigma_{A, 2}=\sigma_{B} \frac{\cos ^{2} \theta_{B}\left(L_{k}-e\right)}{\cos \theta_{A, 2} \sin \theta_{A, 2} d_{k}+\cos ^{2} \theta_{A, 2} e_{2}}$

In Eq. (27), the relationships in (21)-(24) have been used to establish a relation between $\sigma_{A, 2}$ and $\sigma_{B}$. Finally, equilibrium requirements for Triangle $I I$ lead to:

$F_{l}-C_{l, 2}-P_{l, 2}=0$

$F_{t}-C_{t, 2}-P_{t, 2}=0$

$F_{t} \frac{e+e_{2}-e_{1}}{2}-C_{l, 2} \frac{d_{k}}{2}-C_{t, 2} \frac{e+e_{2}}{2}=0$

\subsection{Global equilibrium for Solutions 1 and 2}

With reference to the test specimen depicted in Fig. 2, the global equilibrium conditions can now be used to establish relations between the external load, $V$, and the internal stress resultants defined above. In the longitudinal direction, $l$, the applied load is balanced by the stress resultants $A_{l, i}$ and $B_{l}$ stemming from Struts $A$ and $B$, respectively, where $i=1$ for Solution 1 and $i=2$ for Solution 2 . The resultant $B_{l}$ only exists for Solution 2. The relation reads:

$n A_{l, i}+(n-1) B_{l}=V$

where $n$ is the number of shear keys in the connection.

In the transverse direction, where there is no external load, the stress resultants of the struts must be outbalanced by tension in the transverse U-bar loops crossing the connection. This condition can be written as follows:

$n A_{t, i}+(n-1) B_{t}-(n+1) A_{s} \sigma_{s}=0$

where $A_{s}$ is the total cross sectional area of transverse reinforcement in one loop connection and $\sigma_{s}$ is the stress in the reinforcement. Similar to Eq. (31), $B_{t}$ vanishes when applied to Solution 1 . It should be noted that the equation for global moment equilibrium may serve as a check of the calculated stress distribution in the joint.

\subsection{Yield condition for reinforcement}

The stresses carried by the U-bars must fulfill: $\sigma_{s} \leqslant f_{y}$

By utilizing Eqs. (32) and (8), the yield condition (Eq. (33)), may be reformulated in terms of the stress carried by Strut $A$ in Solution 1:

$\sigma_{A, 1} \leqslant \frac{n+1}{n} \frac{A_{s} f_{y}}{\cos ^{2} \theta_{A, 1} h_{k} e}$

For Solution 2, Eq. (33) may in a similar way be reformulated as a requirement to $\sigma_{B}$ :

$\sigma_{B} \leqslant \frac{(n+1) A_{s} f_{y}\left(\tan \theta_{A, 2} d_{k}+e_{2}\right)}{\cos ^{2} \theta_{B} h_{k}\left(L_{k}-e\right)\left((n-1)\left(\tan \theta_{A, 2} d_{k}+e_{2}\right)+n e\right)}$

This requirement in fact also contains the condition for the stress in Strut $A$, cf. Eq. (27).

\subsection{Failure criteria for joint mortar}

In the following, the failure criteria adopted in the analytical lower bound model to describe the joint mortar will be discussed. Distinction is made between zones with uniaxial compression and zones with biaxial compression. The tensile strength of the mortar is neglected and the uniaxial compression strength is $f_{c}$. For Struts $A_{i}$ and $B$ carrying uniaxial compression, the stress level is limited to:

$\sigma_{A, i} \leqslant v f_{c}, \quad i=1,2, \quad v \leqslant 1$ 
$\sigma_{B} \leqslant v f_{c}, \quad \nu \leqslant 1$

where $v$ is the effectiveness factor. This factor normally takes into account the material brittleness as well as the strength reduction due to cracking and tensile strains perpendicular to the struts. It is argued that in the present lower bound problem, with steep direct strut actions within a narrow and long strip of mortar, the effect of tensile strains perpendicular to the struts may be neglected. Hence, $v$ mainly accounts for the material brittleness. In the following, $v$ will be taken as unity when the analytical lower bound model is evaluated against the numerical calculations (because $v=1$ was used in the numerical calculations). However, when using the analytical lower bound model to compare with its upper bound counterpart [1] and with test results, a value of $v=0.89$ is adopted as a qualified estimate of the effect of material brittleness. This value is obtained from the formula, $v=\left(f_{c, 0} / f_{c}\right)^{1 / 3}$ proposed in the fib Model Code [18], with $f_{c, 0}=30 \mathrm{MPa}$.

Normally, concrete/mortar is identified as a modified Coulomb material, which means that $f_{c}$ will also be the strength in a biaxial compression field. However, as shown e.g. by Kupfer et al. [19], the strength of concrete under biaxial compression may be larger than the uniaxial strength. Furthermore, as the areas with biaxial compression represent nodal zones in the model, the effectiveness factor can here be taken as $v=1$, also in practice. This means that the failure criterion for zones with biaxial compression may be expressed as:

$\sigma_{2} \leqslant c f_{c}, \quad c \geqslant 1$

where $c$ can be interpreted as a strength enhancement factor and $\sigma_{2}$ is the largest principal compressive stress. Test results of Kupfer et al. [19] showed that $c$ depends of the $\sigma_{2} / \sigma_{1}$-ratio $\left(c=1.27\right.$ for $\sigma_{2} / \sigma_{1}=2$ and $c=1.16$ for $\left.\sigma_{2} / \sigma_{1}=1\right)$. In the following, $c$ is taken as unity when the analytical lower bound model is evaluated against the numerical calculations (in order to be consistent with the assumptions made for the numerical model). However, for comparison with the upper bound model and with test results, a qualified estimate of $c=1.15$ is adopted. This value is slightly higher than the recommendation of the fib Model Code [18] for biaxially compressed nodes.

Due to the assumption of zero tensile strength, the following limitation also applies to the biaxially stressed areas:

$\sigma_{1} \geqslant 0$

\subsection{Failure criterion for interface}

As an averaged description, the interface between mortar and precast elements with keys may be categorized as very rough, with a pseudo cohesive resistance and a high pseudo frictional coefficient (see e.g. Eurocode 2 [20]). However, in a detailed calculation where the geometry of the keys is taken into account, the mechanical properties of the real interface should be used. This means that the properties of the formwork have an influence on the failure criterion of the interface. Hence, like for the numerical model, the following Coulomb friction criterion is adopted for the interface:

$\left|\tau_{n t}\right| \leqslant \mu \sigma_{n}$

where $\tau_{n t}$ is the shear stress on the boundary of the shear keys and $\sigma_{n}$ is a compressive normal stress acting on the same boundary, e.g. $\left(\sigma_{n}, \tau_{n t}\right)=\left(\sigma_{t, I I}, \tau_{t l, I I}\right)$. It should be noted that Eq. (40) does not contain a cohesion term. The main argument for neglecting the cohesion is that smooth formwork was used to cast the reinforced concrete elements for the experimental program (smooth formwork is commonly used also in practice). Thus any small cohesive resistance in the interface may have (partly or completely) vanished at the ultimate limit state. The coefficient of friction will in the following be taken as $\mu=0.75$, similar to the assumption of the numerical model. The friction criterion implies that the stress resultants, $C_{l, i}$ and $C_{t, i}$, see Figs. 7(b) and 9(b), must fulfill the following condition:
$\left|C_{l, i}\right| \leqslant \mu C_{t, i}, \quad i=1,2$

For the inclined part of the shear key, the friction criterion, expressed in terms of the resulting forces, can be established as:

$\left|\frac{P_{l, i} \sin \theta_{k}-P_{t, i} \cos \theta_{k}}{P_{t, i} \sin \theta_{k}+P_{l, i} \cos \theta_{k}}\right| \leqslant \mu, \quad i=1,2$

\subsection{Optimization of lower bound solutions}

By examining the geometrical and equilibrium conditions of Solution 1 as well as 2 , it may be shown that the problems are indeterminate with two free optimization parameters, namely the parameter $e$ and one of the statical parameters. The resultant $C_{l, i}$ will in the following be chosen as the statical optimization parameter.

If the interface is not utilized to transfer shear stresses, $C_{l, i}$ will vanish and the solution will eventually be identical to the single strut solution suggested by Christoffersen [7]. Therefore, to obtain better solutions, the interface friction must be utilized as much as possible. Hence, $C_{l, i}$ should be taken as large as possible. According to Eq. (41), this implies:

$C_{l, i}=\mu C_{t, i}, \quad i=1,2$

By choosing the relation given in Eq. (43), the only remaining parameter left for optimization of the load carrying capacity is $e$. The optimization is naturally subjected to the strength constraints established in Sections 5.4 and 5.5. Results are presented in the following.

\section{Verification of analytical lower bound solutions}

The results obtained by FELA (which are optimal under the assumptions made) will in the following be used to verify the analytical lower bound solutions. The purpose is to investigate if the analytical solutions actually capture the main tendencies of the numerical results. Calculations have been carried out based on the properties and parameters of the test specimens. The results, in terms of normalized shear stresses versus the key depth, can be seen in Fig. 10(a), where the result of the single strut solution [7] is also shown. The nominal shear stress has been determined as follows:

$\tau=\frac{V}{n h_{k} L_{k}}$

where $V$ is calculated from Eq. (31). The full red curve in Fig. 10(a) corresponds to the upper envelope of Solutions 1 and 2 and represents the optimal results provided by the analytical lower bound model. It can be seen that Solution 2 applies to larger key depths $\left(d_{k}>8 \mathrm{~mm}\right)$ whereas Solution 1 provides better results for smaller key depths. For key depths larger than $13 \mathrm{~mm}$, Triangle $I$ vanishes in Solution 1 , as the length $a$ becomes smaller than $e_{1}$. In this case $\sigma_{A, 1}$ will act only on the inclined part of the key corner, however, as the capacity is less than Solution 2, it is not calculated. Contrary to the single strut solution, the present model actually provides a significant capacity in the limiting case of $d_{k}=0 \mathrm{~mm}$ (i.e. when the design is no longer a keyed connection). In this case, there is no nodal zone and the compression from the diagonal struts is transferred through the interface by pure shear-friction. Fig. 10(b) depicts the optimal value of $e$ versus the key depth. At the transition point, the optimal value of $e$ for Solution 1 is different from that of Solution 2. This underlines that Solution 2 is not to be considered as an extension of Solution 1, which is also seen in the fact that the transition between the two solutions is not smooth.

Nevertheless, it is found that the analytical model provides results that are almost identical to the numerical results obtained by FELA (Fig. 10(a)). A small deviation is observed around the transition between Solution 1 and Solution 2. However, the deviation is insignificant compared to the overall agreement. This strong correlation shows that the analytical model is close to the optimal solution. In this context it 


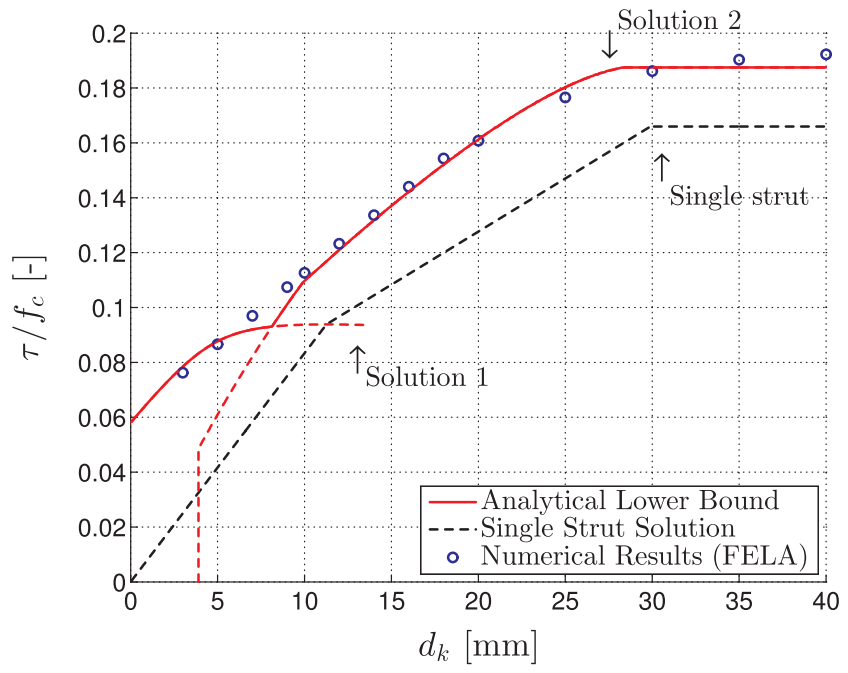

(a)

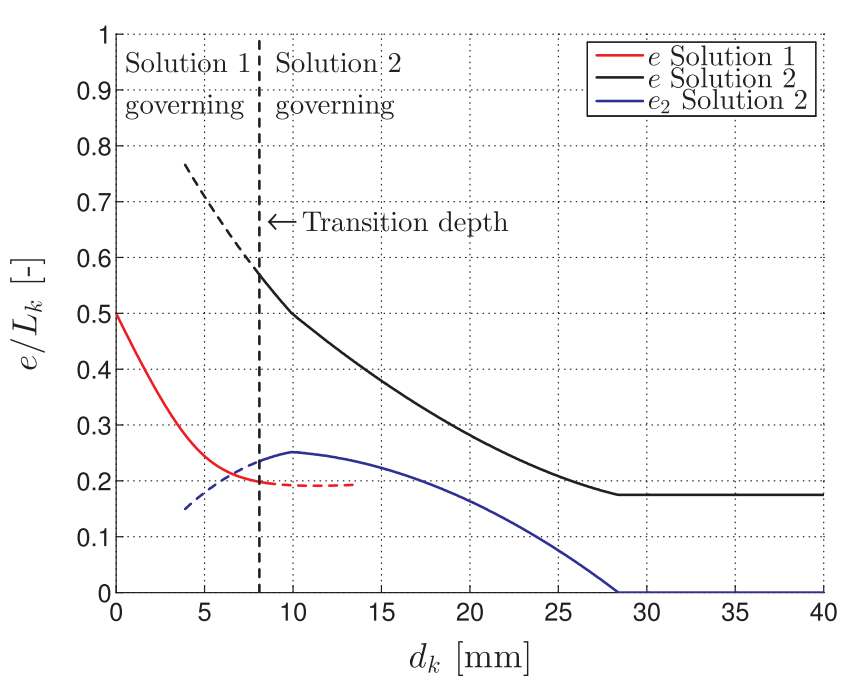

(b)

Fig. 10. (a) Comparison of analytical and numerical lower bound models and (b) the optimal distance $e$ calculated for Solutions 1 and 2 .

should be noted that optimality here only refers to the best results that can be obtained by the assumptions made and not necessary the 'true' results. Note further that other geometries and reinforcement degrees may favor other stress fields not captured by the two developed analytical solutions.

It can be seen in Fig. 10(a) that the analytical model as well as FELA estimate a higher capacity than the single strut solution developed in [7]. This is partly related to the inclusion of friction in the grout-topanel interface at the keyed areas.

Fig. 11 depicts the stresses of Solution 1 versus the key depth. It can be seen that the maximum compressive principal stress, $\sigma_{2, I}$, acting in Triangle $I$ is governing in the entire interval of $d_{k}$, where Solution 1 is optimal. Moreover it appears that the minor principal stress, $\sigma_{1, I}$, is also compressive and that the stress in Strut $A, \sigma_{A, 1}$, is well below $\nu f_{c}$ for all key depths. The magnitudes of the stresses depicted in Fig. 11 indicate a local failure of the key corners (only Triangle $I$ is critical). This is in agreement with test results for specimens with small key depths.

The stresses of Solution 2 are plotted in Fig. 12. It can be seen that $\sigma_{1, I I}=0$ when the key depth is approximately $4 \mathrm{~mm}$. This stress component in fact becomes negative (i.e. tension) for lower values of $d_{k}$, which means that Solution 2 does not provide valid results for smaller

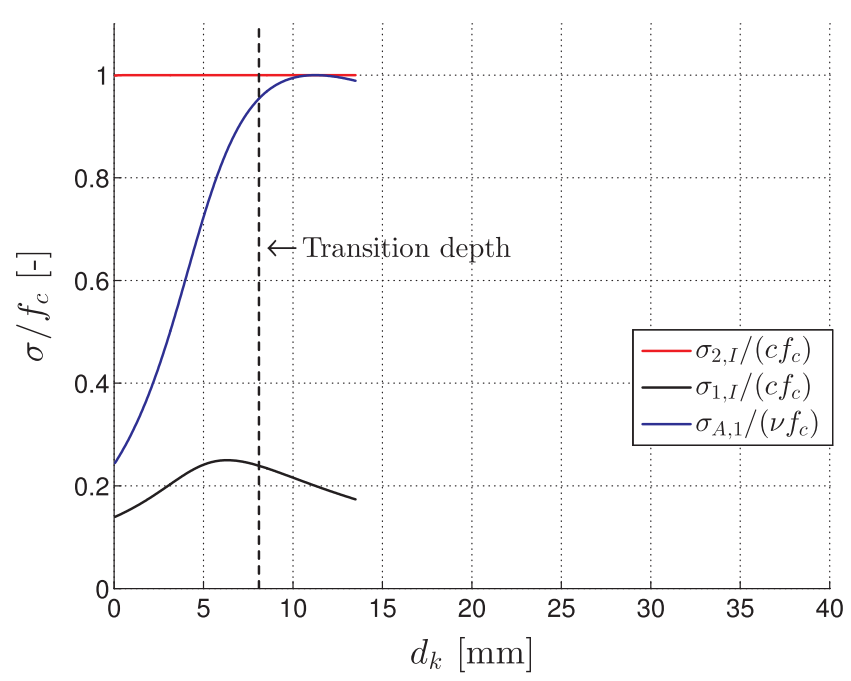

Fig. 11. Normalized stresses versus key depth in Solution 1 , note that $c=1$ and $\nu=1$.

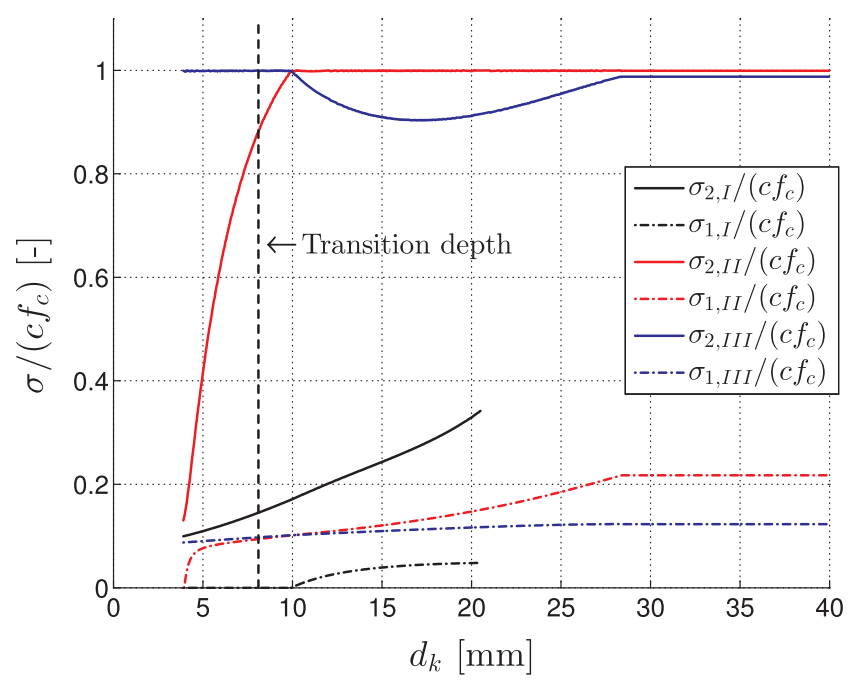

Fig. 12. Normalized stresses versus key depth in Solution $2, c=1$.

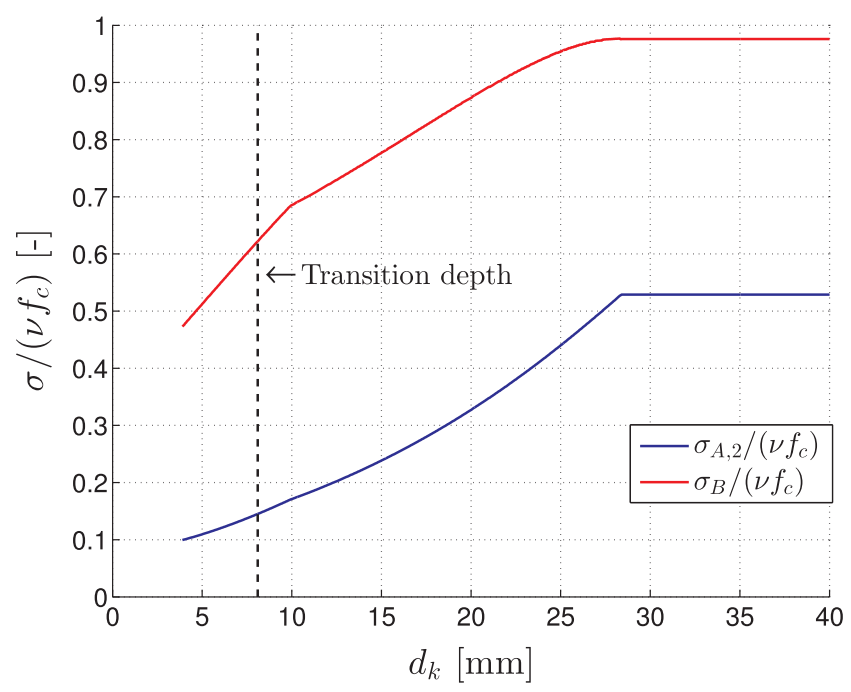

Fig. 13. Variation of $\sigma_{A, 2}$ and $\sigma_{B}$ as function of key depth in Solution $2, v=1$.

key depths (at least not for the assumed material parameters and geometry considered). Furthermore, it can be seen that $\sigma_{2, I I I}$ is the governing stress component for key depths between $4 \mathrm{~mm}$ and $10 \mathrm{~mm}$, 


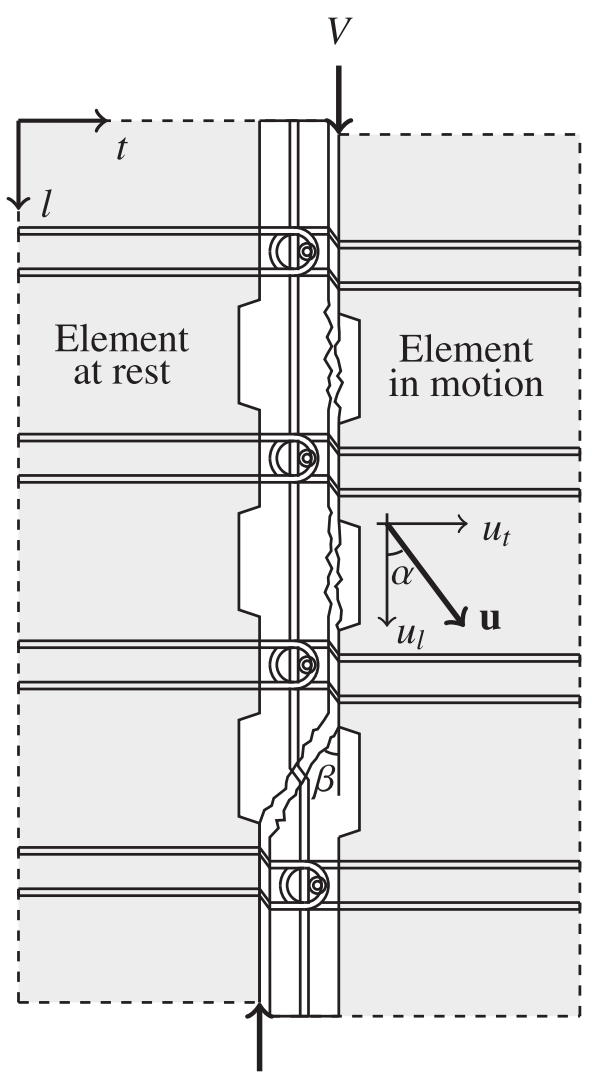

V

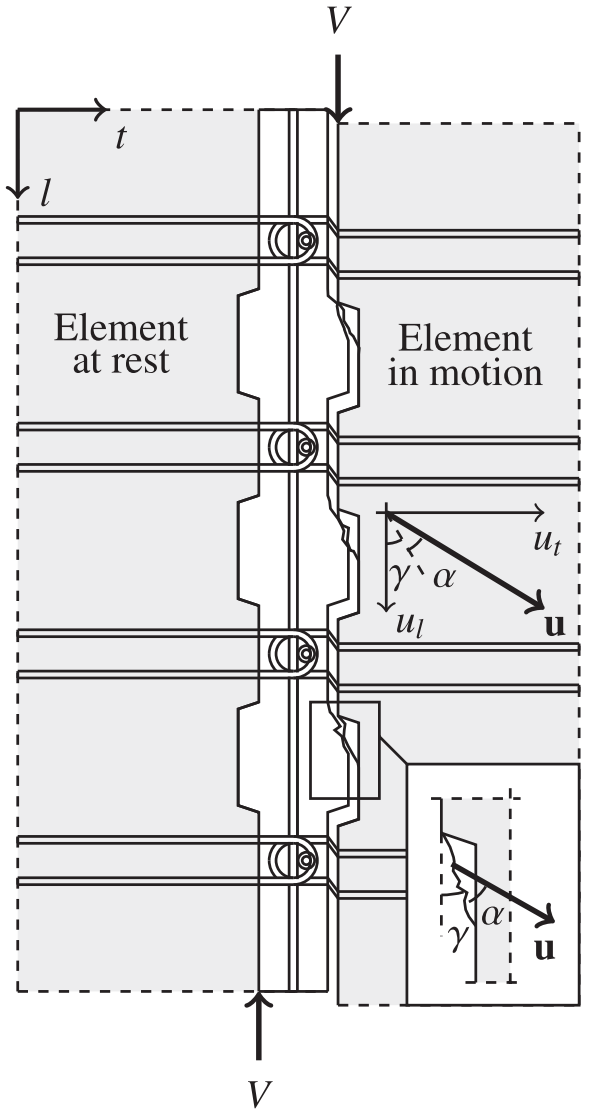

(b)
Fig. 14. Collapse mechanisms considered in upper bound model, (a) complete key shearing combined with diagonal yield line and (b) local key corner failure, illustrations from [1].

(a)

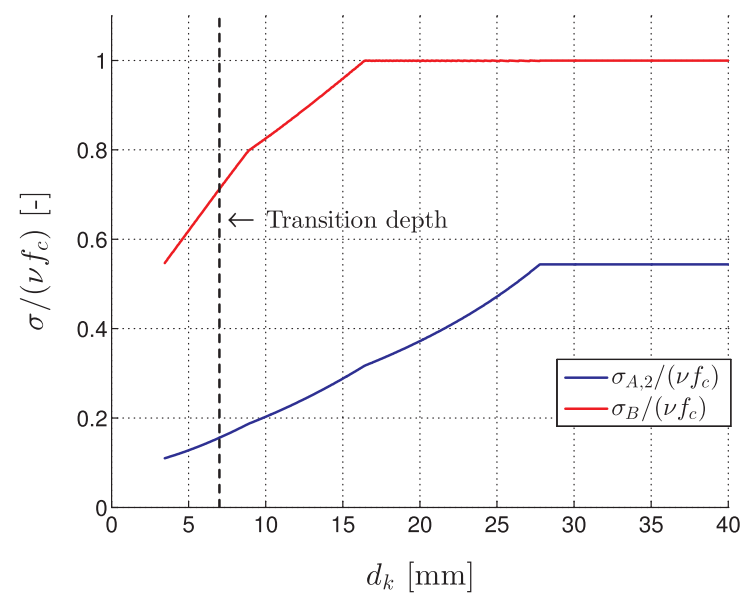

(b)

Fig. 15. (a) Comparison of upper and lower bound models with test results, (b) stresses in Struts $A$ and $B$ in Solution 2 .

while $\sigma_{2, I I}$ is governing for larger key depths. Triangle $I$ vanishes at a key depth of approximately $21 \mathrm{~mm}$. As $\sigma_{A, 2}<v f_{c}$, the stress can be safely transferred without considering a nodal zone. At a key depth of about $28 \mathrm{~mm}$, the maximum effective depth according to Eq. (14) is introduced and the capacity cannot be increased further beyond this key depth.

Fig. 13 shows how the stresses in Struts $A$ and $B$ vary in Solution 2 . It can be seen that $\sigma_{B}$ is larger than $\sigma_{A, 2}$ in the entire interval of key depths. At the transition to the effective key depth $\left(d_{k} \approx 28 \mathrm{~mm}\right)$, the stress in Strut $B$ has almost reached the capacity of $\nu f_{c}$, however, it remains slightly below. These results of course reflect the modeled geometry and adopted material parameters $v=c=1$.

\section{Comparison of analytical lower and upper bound models}

In the following, the analytical lower bound model will be compared with the previously developed upper bound model [1]. It is not expected that the two models lead to identical results (i.e. a theoretically exact solution) since they are not fully based on the same set of assumptions. For instance, plane stress condition is assumed in the lower bound model while plane strain condition is imposed in the upper bound model. However, the comparison can be used to evaluate the 
tendencies of the two models and in particular the gap between them. Eventually, by comparison of both models with test results, a qualified discussion of the effectiveness factor adopted in the pure upper bound approach [1] can be carried out.

The upper bound model presented in Ref. [1] is based on two basic collapse mechanisms reflecting local key corner failure and complete key shearing, respectively, see Fig. 14. The interface properties between mortar and the precast elements are neglected and the mortar is treated as a modified Coulomb material with zero tensile strength and with an internal angle of friction taken as $\varphi=30^{\circ}$. The assumption of plane strain condition implies that the angle of displacement, $\alpha$, due to the normality condition cannot be smaller than $\varphi$, i.e. $\alpha \geqslant 30^{\circ}$. For a detailed derivation of the upper bound solution, the reader is referred to [1]. It should be noted that the upper bound solution, in contrast to the lower bound counterpart, can be formulated as closed-form equations and is therefore easier to use in practice.

The results of the upper bound and lower bound models can be seen in Fig. 15(a). As stated in the previous, $v=0.89$ is adopted for the uniaxial compression struts while $\nu=1$ and $c=1.15$ are used for the biaxial compression zones in the lower bound model. Such a distinction between types of stress field can of course not be made in the upper bound model. Therefore, $v=0.89$ has been used when determining the dissipation in all the yield lines in the upper bound model. The gap between the upper and the lower bound solutions (Fig. 15) is however not due to the difference in the material parameters. The gap would in fact have been larger, had the lower bound calculations also been based on $v=0.89$ and $c=1$ everywhere. It is mainly the assumption of plane strain condition versus plane stress condition that has an influence on the observed gap. In addition, other more sophisticated collapse mechanisms (not yet analyzed) may lower the upper bound results.

Another discrepancy between the two models should also be pointed out. A closer look at the two solutions (in Fig. 15) in the vicinity of $d_{k}=0 \mathrm{~mm}$ reveals that the upper bound solution is lying below the lower bound solution. This difference has no practical significant but is apparently inconsistent with the extremum theorems of plasticity. The reason is to be found in the fact, that the interface is assigned a friction failure criterion, Eq. (40), in the lower bound model while this criterion is ignored in the upper bound calculations. To obtain results consistent with the extremum theorems, the upper bound calculations should be modified to include the friction criterion for the interface and at the same time fulfill the normality condition at the interface. It may in that case be shown, that the upper bound solution will lie above the lower bound counterpart and that the two solutions will yield exactly the same result at the limiting case of $d_{k}=0 \mathrm{~mm}$.

In the present calculations, the upper bound model reaches the upper limit (corresponding to complete key shearing) at $d_{k} \approx 13 \mathrm{~mm}$. This is actually close to $d_{k}=16 \mathrm{~mm}$, which in the test series corresponds to the transition between the two failure modes. The lower bound Solution 2 on the other hand, reaches an upper limit at $d_{k} \approx 28 \mathrm{~mm}$ corresponding to the maximum effective key depth (Eq. (14)). Furthermore, in Solution 2, the Triangle II is critical when $d_{k}$ is between approximately 9 to $17 \mathrm{~mm}$ while Strut $B$ is stressed to $v f_{c}$ and therefore critical for $d_{k}$ larger than $17 \mathrm{~mm}$ (see Fig. 15(b)). For $d_{k}>17 \mathrm{~mm}$, the thickness of Strut $B$ increases with increasing $d_{k}$ which explains the increase of the capacity for $d_{k}$ between 17 and $28 \mathrm{~mm}$. As seen in Fig. 15(b), Strut $A$ of Solution 2 is at no point critical. The fact that only Strut $B$ is critical when Solution 2 reaches the upper limit makes it rather difficult to relate the result to a failure mechanism involving complete key shearing. This simply underlines that Solution 2 (although it may be optimal subjected to the assumptions made) is still a lower bound and thus a safe model for the real ultimate behavior of the connection.

It is important for practical application that the two models (developed independently of each other) in fact display the same overall tendencies, namely a shear capacity that increases with increasing key depth until an upper limit has been reached. This improves the reliability of the results. However, the most correct solution would probably be somewhere between the two models since in reality, the connection is not in a state of plane strain, nor plane stress, but somewhere in between. This is clearly seen in the fact that the test results as plotted in Fig. 15(a) are all lying in between the results of the upper and lower bound models. Hence, an important conclusion that can be drawn from the comparison in Fig. 15 is that the effectiveness factor adopted in the pure upper bound approach (see Ref. [1] for details) not only reflects the material brittleness but also partly contains an empirical reduction to compensate for the ideal assumption of plane strain. In this context, it is interesting to note that the width, i.e. $b$ shown in Fig. 2, must have an influence on the stress and strain conditions in the connection, but this parameter is absent in the failure mechanisms based on the plane strain assumption that were considered in Ref. [1]. Hence, it is reasonable to believe that the effectiveness factor of the pure upper bound approach also compensates for the influence of $b$, which is not considered theoretically. The lower bound model, on the other hand, includes the width, $b$, as an important parameter. Still, if the plane stress lower bound solution should be calibrated to fit the test results (Fig. 15), then artificially higher values of $v$ and $c$ would be required, most probably to compensate for the triaxial stress state that in reality would develop locally in the joint mortar.

It might be too optimistic to expect that a more correct/realistic solution can be developed which at the same time is as user-friendly as the closed-form upper bound solution. The upper bound model will therefore still have preference from a practical point of view, even though it has to be used in conjunction with an effectiveness factor that not only accounts for the real material behavior but also functions as an adjustment parameter to compensate for the unsafe nature of upper bound solutions. Awareness of this is important when applying the upper bound model to practical cases, which deviate significantly from the experimentally tested configurations. In such situations, the lower bound model presented in this paper will be useful.

\section{Conclusions}

This paper presented push-off tests of a recently developed keyed shear connection design for precast concrete wall elements. The investigation focused on the influence of the key depth on the failure mode and the load-displacement response of the connections. The experimental observations include:

- Connections with smaller key depths failed by local key corner shearing while failure by complete key shearing was observed for connections with larger key depths

- The maximum capacity (first peak load) was related to failure of the keys and increased with increasing key depth until complete key shearing became the critical failure mode

- The residual load level (beyond the first peak load) is relatively higher for connections suffering local key corner shearing

The experimental observations suggest that for practical applications the connection should be designed to be governed by local key corner crushing as this improves the ductility. In addition to the experimental results, an analytical lower bound model was developed for prediction of the first peak capacity. The model was validated with numerical calculations based on finite element limit analysis. The model differs from existing analytical lower bound solutions for keyed connections in the following way:

- The load can be carried by a combination of struts spanning over one or two indentations

- Local strength increase at nodal zones and effects of interface friction are accounted for

- The nodal zones can be subjected to non-hydrostatic biaxial stress 
conditions

The lower bound model shows similar tendencies as a previously developed upper bound model and the test results fall within the gap between the two solutions. From the comparison, it can be concluded that the lower bound solution is a safe one due to the assumption of plane stress condition while the plane strain assumption adopted in the upper bound solution is theoretically unsafe and must be compensated for by adjustment with test results. This is reflected in the relatively low effectiveness factor that has to be applied. The upper bound solution should therefore only be used for configurations within the range covered by tests. In other cases, the lower bound model is applicable although it is more complicated to use. In conclusion, it can be stated that the paper has contributed to a more complete theoretical basis for practical design of keyed connections.

\section{Acknowledgment}

The experimental program was financially supported by the Danish Association for Precast Concrete Elements and the COWI Foundation. The test elements were produced at CRH Concrete and the experimental work was conducted with support from M.Sc. R.M. Hou and M.Sc. J.S. Olsen. The authors gratefully acknowledge these valuable contributions.

\section{Appendix A. Lower bound finite element limit analysis (FELA)}

As discussed in Section 4, FELA can be considered as a special case of the general finite element method, where a rigid-plastic material model is assumed. Unlike the finite element method, however, FELA is a so-called direct method where the collapse load is determined in a single step and no incremental procedure is needed. The method is therefore rather efficient and numerically stable for calculation of the collapse load of structures.

The fundamental idea of the method is to formulate a given limit analysis problem as a convex optimization problem, where the ultimate load is maximized. In order to obtain a lower bound solution, the determined stress field must be statically admissible and safe. This is ensured by a set of linear equality constraints, representing the equilibrium conditions, as well as a set of convex inequality constraints, representing the convex yield conditions. The general form of the optimization problem is given below:

$\begin{array}{cc}\text { maximize } & \lambda \\ \text { subject to } & B^{T} \sigma=p \lambda+p_{0} \\ & f\left(\sigma_{i}\right) \leq 0,\end{array}$$$
i=1,2, \ldots, m
$$

The external load comprises a constant part, $p_{0}$, and a scalable part, $p \lambda$, where $\lambda$ is the load factor, which is sought to be maximized. The external load is balanced by the stress field described by the vector $\sigma$ via the linear equilibrium equations, $B^{T} \sigma=p \lambda+p_{0}$, where $B^{T}$ is the equilibrium matrix. The yield function $f\left(\sigma_{i}\right)$ is checked in the $m$ points to ensure a safe stress field. For concrete, the Mohr-Coulomb yield criterion is commonly used which can be expressed as conic constraints [21,22].

The equilibrium matrix, $B^{T}$, depends on the chosen lower bound finite elements and discretization. In this paper, lower bound plane stress elements have been used together with bar and interface elements, representing the reinforcement and grout-to-panel interfaces of the keyed joint.

\section{References}

[1] Sørensen JH, Hoang LC, Olesen JF, Fischer G. Test and analysis of a new ductile shear connection design for RC shear walls. Struct Concr 2017;18(1):189-204.

[2] fib. Bulletin 43: structural connections for precast concrete buildings. Federation international du béton, Lausanne, Switzerland; 2008.

[3] Hansen K, Kavyrchine M, Melhorn G, Olesen S $\emptyset$, Pume D, Schwing H. Keyed shear joints - SBI rapport 97. Tech rep. Danish Building Research Institute; 1976.

[4] Sørensen JH, Hoang LC, Olesen JF, Fischer G. Tensile capacity of loop connections grouted with concrete or mortar. Mag Concr Res 2017;69(17):892-904.

[5] Jensen BC. Nogle Plasticitetsteoretiske Beregninger af Beton og Jernbeton (English: Some applications of plastic analysis to plain and reinforced concrete). Report 111. Ph.D. thesis. Lyngby: Technical University of Denmark, Institute of Building Design; 1976.

[6] Jørgensen HB, Hoang LC. Tests and limit analysis of loop connections between precast concrete elements loaded in tension. Eng Struct 2013;52:558-69.

[7] Christoffersen J. Ultimate capacity of joints in precast large panel concrete buildings, series R No 25. Ph.D. thesis. Lyngby: Technical University of Denmark, Department of Structural Engineering and Materials; 1997.

[8] Nielsen MP, Hoang LC. Limit analysis and concrete plasticity. 3rd ed. Boca Raton: CRC Press, Taylor \& Francis Group; 2011.

[9] Herfelt MA, Poulsen PN, Hoang LC, Jensen JF. Numerical limit analysis of keyed shear joints in concrete structures. Struct Concr 2016;17(3):481-90.

[10] Nielsen MP. Om jernbetonskivers styrke (English: On the strength of reinforced concrete discs). Polyteknisk Forlag; 1969.

[11] Muttoni A, Schwartz Joseph, Thürlimann Bruno. Design of concrete structures with stress fields. Basel (Switzerland): Birkhäuser Verlag; 1997.
[12] Pistoljevic N, Nielsen MP. HSTO-metoden. Plasticitetsteori for armerede betonskiver. Anvendelse af homogene spændingstilstande i trekantformede områder. Proc Danish Soc Struct Sci Eng 2009:80(2):19-54.

[13] Calladine CR. Simple ideas in the large-deflection plastic theory of plates and slabs. In: Heyman J, Leckie FA, editors. International conference on the applications of plastic theory in engineering design, Cambridge, UK; 1968. p. 93-127.

[14] Bræstrup MW. Dome effect in RC slabs: rigid-plastic analysis. J Struct Div - ASCE 1980;106(6):1237-53.

[15] Belenkiy LM. Upper-bound solutions for rigid-plastic beams and plates of large deflections by variation principles. J Eng Mech 2007;133(1):98-105.

[16] Sørensen JH, Hoang LC, Olesen JF, Fischer G. Testing and modeling dowel and catenary action in rebars crossing shear joints in RC. Eng Struct 2017;145:234-45.

[17] Dahl KKB. Construction joints in normal and high strength concrete. Tech rep. Lyngby: Technical University of Denmark, Department of Structural Engineering; 1994.

[18] fib. Model code for concrete structures 2010. Lausanne (Switzerland): Wilhelm Ernst \& Sohn; 2013.

[19] Kupfer H, Hilsdorf HK, Rüsch H. Behavior of concrete under biaxial stresses. ACI Struct J 1969;66(8):656-66.

[20] CEN. EN1992-1-1 Eurocode 2: design of concrete structures Part 1-1: General rules and rules for buildings. 3rd ed. European Committee for Standardization, Brussels; 2004.

[21] Krabbenhøft K, Lyamin AV, Sloan SW. Formulation and solution of some plasticity problems as conic programs. Int J Solids Struct 2007;44(5):1533-49.

[22] Bisbos CD, Pardalos PM. Second-order cone and semidefinite representations of material failure criteria. J Optimiz Theory Appl 2007;134(2):275-301. 